\title{
Wong, Lindsay. (2018). The Woo Woo: How I Survived Ice Hockey, Drug Raids, Demons, and My Crazy Chinese Family. Vancouver: Arsenal Pulp Press.
}

\author{
Reviewed by: Tijana Srdic, MacEwan University
}

Lindsay Wong's book, "The Woo-Woo" is a memoir written about her childhood and growing up with a Chinese immigrant family in Vancouver. In Wong's memoir, the term 'WooWoo' was used to characterize the spirits or ghosts that possessed the living, and caused them to act different than what was deemed to be normal. There was always a mention of the 'Woo-Woo', the term the Wong family used to explain why someone was acting abnormally. Wong highlighted some key themes within her book, but the few that stuck out the most were adolescence, parenting, and mental illness.

Wong's reminiscence of her teenage years can be relatable to many adults now, who have all experienced the awkwardness of hitting the age of teen hood. In the memoir, Wong's biggest hurdle as a teen appeared to be making friends. Her first friend, 'Pizza Head' (who was given that nickname because of the many itchy sores on her scalp) ends up being a neighbor from across the street, appearing to be a daughter of a Chinese family deeply involved in the marijuana drug trade. This friendship was forced, and if anything, unnatural, and what really drew the line for Lindsay was when 'Pizza Head' told her, "That Woman (Pizza Head's mother) says I have to be friends with you, or I can't use my credit card anymore. That Woman says our job is to make the entire block like us, so you better take this stupid necklace. If I don't like you, then your parents won't like us." (p. 54) Lindsay struggled with this friendship because she realised very shortly that the relationship was very superficial, and transactional. Throughout her teenage years, she makes 
seldom friendships and bonds, because much like with 'Pizza Head', the other relationships were forced, such as her friendship with Robin. Robin was a handicapped girl from school who Lindsay had to accompany everywhere, assisting her with homework. This friendship was forced upon her by her student guidance counsellor who stated "Lindsay, your teachers say you're aggressive and display anti-social tendencies. You don't have any empathy, and the other kids have told me that they are afraid of you. Normally, I have to teach students to be less passive and more assertive. But I need you to learn to control yourself, okay...?” (p. 127) The idea of Lindsay being paired up with Robin was so that Lindsay could form a bond with this girl, and hopefully learn to have some empathy. However, Lindsay blocked her emotions off, and figured out how to create a symbiotic relationship between the two, whilst achieving personal gain by getting to skip classes as an example. Lindsay found this to be a major perk of the relationship. In her adolescent years, the only friendships she seemed to make were ones that were either forced by her school, or bribed by her parents, "Back then...I saw every single person, as intricate puzzle pieces to be cautiously positioned into my grand, spastic narratives and dirty, absurdist schemes.” (p. 181)

It seemed like Lindsay viewed as every relationship as a transaction, how can they benefit me and what can I get out of them? Mainly this is a cause of how her father raised Lindsay to believe that everything in this world had a monetary value and must be cashed in on. "Don't be retarded." My father said, putting his headphones on. "I have to go to work and make money." (p. 171) Everything had a profit or gain, and the Wong family never wasted a cent, or their precious time on something that didn't further their success. There seemed to be a big emphasis placed on this, when Wong illustrated her family dynamic. Her family's choice of parenting was instilled 
with old-school, Chinese values, whist trying to blend with the Canadian heritage. The parenting style identified in this book would be considered authoritarian, meaning high levels of control over the child, and low levels of acceptance of the child. She was placed in a girl's hockey team, where Lindsay looked for approval from her parents, by being a blood-thirsty hockey player, the enforcer of the team, "I was going to be okay, and I was going to be victorious. I did not care if my team won, only if I won MVP overall. This was my deeply troubling mindset at the time: to appease my father and fix my mother.” (p. 64) Much of Lindsay’s behaviour was fuelled by her parents, and without Lindsay accomplishing such goals, her parents scolded and shunned her for disappointing them. Through her illustration of the Wong family's style of parenting, it painted a clear picture of how authoritarian parenting can cause the opposite of what a good outcome in raising a child would look like. Her parents offered her strict rules, accompanied with cold interactions with Lindsay, which most likely caused her to act out.

Mental illness existed within the family; however, such subjects are taboo within the Chinese culture, and it is shameful to admit that one might be dealing with a mental disorder. So, the Wong family would use the term 'Woo-Woo' whenever someone in the family acted mentally unwell. As an example, Lindsay's mother 'Quiet Snow' who had a mixture of mental illnesses would frequently be called 'Woo-Woo'. According to Lindsay, "The ghosts had possessed my mother again." (p. 21). This theme can be related to many, as there is a stigma placed upon being sick, or receiving treatment for it. "Be aware," my aunt said, as she escorted my grandmother to our front door. "I try to fix Poh-Poh, but there are still many ghost. She just throw herself down the stair because she think her head is not attached to her body" (p. 105). The way that the Wong 
family dealt with mental illness, through blaming a spirit for attaching itself to Lindsay's mother, is comparable to how mental illness is stigmatized within our society, and how people prefer to not acknowledge that somebody might be really sick, and instead turn to alternative ways of explaining their mental illness (i.e. being possessed by a spirit or ghost).

Wong's memoir is served as a mini autobiography of her teen years and serves as an explanation for why she had been who she was as an adolescent, mainly. However, this book also serves a purpose to shed some light on topics such as mental illness, parenting, and adolescence. The way Wong chose to talk about certain topics, seemed to be excellent because she spoke through experience, and storytelling. The main lesson in this story that I took from it was that mental illness, although a hushed subject, is very prevalent in today's society, and many people who surround us are dealing with in in one way or another, from the mildest forms to the most extreme. Wong's book, "The Woo-Woo" was made for an audience ranging from teenagers to adults; teenagers, who may relate to the book in some form, or adults who are studying the field of psychology or sociology. This book fit very well with the 'Introduction to Family' course at MacEwan University, because it shares a person's story about how they grew up different than what your average non-immigrant, Canadian family would typically go through, and I can support this personally. Growing up in an immigrant family, there were things that were definitely done different in my family, compared to others. The parenting style - authoritative, was similar to the Wong family's parenting style. and this did not produce good upbringing results, instead it made me hostile, angry, and made it difficult to relate to others. This book could be an example of how people may look put together on the outside, however everyone has their ghosts or demons that have in one way or another, shaped and formed who they are today. 